\title{
Serum thioredoxin is a diagnostic marker for hepatocellular carcinoma
}

\author{
Jun Li ${ }^{1, *}$, Zhang-Jun Cheng ${ }^{2, *}$, Yang Liu ${ }^{1, *}$, Zhen-Lin Yan ${ }^{1}$, Kui Wang ${ }^{1}$, Dong Wu ${ }^{1}$, \\ Xu-Ying Wan ${ }^{3}$, Yong $\mathrm{Xia}^{1}$, Wan Yee Lau ${ }^{1,4}$, Meng-Chao Wu ${ }^{1}$, Feng Shen ${ }^{1}$ \\ ${ }^{1}$ Department of Hepatic Surgery, the Eastern Hepatobiliary Surgery Hospital, Second Military Medical University, Shanghai, \\ China \\ ${ }^{2}$ Department of General Surgery, the Zhongda Hospital, Southeast University, Nanjing, China \\ ${ }^{3}$ Department of Chinese Traditional Medicine, the Eastern Hepatobiliary Surgery Hospital, Second Military Medical University, \\ Shanghai, China \\ ${ }^{4}$ Faculty of Medicine, the Chinese University of Hong Kong, Shatin, New Territories, Hong Kong \\ *These authors have contributed equally to this work \\ Correspondence to: \\ Feng Shen, e-mail: shenfengehbh@sina.com \\ Keywords: Thioredoxin, hepatocellular carcinoma, biomarker, diagnosis, Chinese \\ Received: December 14, $2014 \quad$ Accepted: February 08, $2015 \quad$ Published: March 19, 2015
}

\section{ABSTRACT}

Here we found that serum levels of thioredoxin were increased in patients with hepatocellular carcinoma (HCC). The optimum diagnostic cutoff for thioredoxin was $20.5 \mathrm{ng} / \mathrm{mL}$ (area under curve [AUC] 0.946 [95\% CI 0.923-0.969] in the training cohort; 0.941 [0.918-0.963] in the validation cohort). High serum concentrations of thioredoxin differentiated HCC from chronic liver diseases and cirrhosis (0.901 [0.875-0.923] in the training cohort; 0.906 [0.870-0.925] in the validation cohort). Furthermore, a higher proportion of patients with very early HCC had positive results for thioredoxin than for alpha-Fetoprotein (AFP) (73.7\% VS.31.6\%; $P<0.0001)$. Among AFP-negative patients with very early HCC, $18(69.2 \%)$ of 26 had positive thioredoxin results. Our results indicate that serum thioredoxin complements measurement of AFP in the diagnosis of HCC, especially in very early disease. Combined model (thioredoxin and AFP) showed a significantly greater discriminatory ability as compared with those markers alone.

\section{INTRODUCTION}

Primary liver cancer is the second most common malignancy, and currently results in 360,000 incident cases and 350, 000 deaths a year in China [1]. In 2008, half of all new cases of liver cancer and related deaths worldwide were estimated to occur in China [2]. Hepatocellular carcinoma (HCC) accounts for $70-80 \%$ of all liver cancers. HCC is the second most common cause of cancer associated death in China [3]. Although surgical resection and liver transplantation provided valid approaches to treat $\mathrm{HCC}$, the 5-year recurrence rate after curative resection is still high, up to $54.1-61.5 \%$ and ultimately results in poor OS [3]. This dismal outcome is due partly to the lack of an effective method for timely diagnosis, which leads to only $30-40 \%$ of patients with $\mathrm{HCC}$ being suitable for potentially curative treatments at the time of diagnosis [4]. Effective diagnostic methods to detect $\mathrm{HCC}$ at an early stage may result in more effective treatment and extend patient survival. However, the lack of symptoms in the early stage of HCC makes early diagnosis for HCC impractical.

The limitations of ultrasound, the primary radiologic screening modality under current use, include its operator dependence and its poor ability to differentiate malignant from benign nodules in the small cirrhotic liver. Although imaging with triphasic computed tomography scan and magnetic resonance imaging can improve the diagnostic performance, these techniques are time consuming and too expensive for widespread screening at the present time [5]. The search of reliable and efficient biomarkers for a diagnostic and prognostic evaluation of HCC is still an open issue.

Currently, a-Fetoprotein (AFP), des-gamma carboxyprothrombin (DCP), and tissue polypeptide antigen are the primary biomarkers used in the diagnosis of HCC [6-8]. 
AFP is the only molecular marker that has been widely used for the diagnosis and detection of HCC. At a cutoff value of $20 \mathrm{ng} / \mathrm{mL}$ of serum, AFP shows $60 \%-80 \%$ sensitivity [9]. However, this sensitivity decreases to about $40 \%$ for the detection of small tumors [10]. In addition, a significant increase in serum AFP level (20-200 ng/ $\mathrm{mL}$ ) is detected in a considerable number of patients with chronic liver disease [11], including $15 \%-58 \%$ of patients with chronic hepatitis and $11 \%-47 \%$ with cirrhosis [11]. Thus, the identification of a biochemical marker with better sensitivity and/or specificity than AFP could be extremely helpful in improving early diagnosis of HCC.

Impairment or ablation of antioxidant enzymes leading to the accumulation of toxic levels of ROS might initiate or promote a variety of human diseases, e.g., neurodegeneration, cancer development, arthritis, and atherosclerosis [12]. Redox control has emerged as a fundamental biological control mechanism. The thioredoxin system plays a key role in regulating the overall intracellular redox balance. It basically comprises the small redox protein thioredoxin, nicotinamide adenine dinucleotide phosphate, in its reduced form (NADPH), and thioredoxin reductase (ThioredoxinR), a large homodimeric selenzoenzyme controlling the redox state of thioredoxin [13]. Thioredoxin exerts many of its biological activities by reducing a variety of protein thiols, usually having a relatively low molecular weight disulfide. The activity of thioredoxin is regulated by NADPH, which in turn is produced by G6PD, the rate-limiting enzyme of the oxidative HMPS cycle. Two thioredoxins have been cloned: a $54 \mathrm{kDa}$ enzyme (thioredoxin 1) that is found predominantly in the cytoplasm and a $56 \mathrm{kDa}$ enzyme (thioredoxin 2) that contains a mitochondrial import sequence [14].

Elevated serum thioredoxin levels have been observed in many diseases, including diabetes [15], chronic kidney disease [16], severe burn injury [17] and coronary disease [18]. Increased thioredoxin expression has been seen in a variety of malignancies and recent evidence suggests that it may be associated with aggressive tumor growth and poor survival [19-21]. Miyazaki et al. [22] found that elevated serum level of thioredoxin in patients with HCC. Herein, the aims of this study were to determine thioredoxin levels in the serum, and to establish the sensitivity and specificity of serum thioredoxin for diagnosing HCC in Chinese patients with HCC.

\section{RESULTS}

\section{Thioredoxin and clinical variables}

In our study, $25 \mathrm{HCC}$ patients (19 with secondary liver cancer from other primary regions and 6 with history of other solid tumors) in training cohort and 34 (24 with secondary liver cancer from other primary regions and 10 with history of other solid tumors) in validation cohort were excluded. Thus, we recruited 1100 participants overall, 520 in the test cohort (180 with HCC) and 580 in the validation cohort (240 with HCC). In the study patients with HCC, 95(52.8\%) were male and median age was 56 years (IQR, 45-64). At diagnosis, 100 (55.6\%) patients were classified into Child-Pugh class A; 60 (33.3\%) patients into class B; $20(11.1 \%)$ patients into class C. There were $40(22.2 \%)$ patients at TNM stage I, 70 (38.9\%) at stage II, 62 (34.4\%) at stage III, and $8(4.4 \%)$ at stage IV. The median tumor size was 6.2 (IQR, 2.5-19.5) cm and the number of patients with solitary tumor was 115 (63.9\%). Each case of presence of PVT and extra-hepatic metastasis was 55 (30.6\%) and 33 (18.3\%), respectively. Baseline characteristics of the HCC and control cases were shown in Table 1.

\section{Main findings}

The median levels of serum thioredoxin was 45.1 (IQR, 28.2-56.0) ng/ml, which was significantly higher than that of healthy subjects, patients with cirrhosis and chronic liver diseases $(P<0.0001$; Figure 1a). Similarly, thioredoxin was also significantly higher as compared to controls in validation cohort (Figure 1b). Although the median concentration of AFP in serum was increased for patients in the HCC group compared with that in healthy controls, as expected $(P<0.0001)$, significant increases were also seen in patients with LC and CLD $(P<0.0001$; Table 1). The relationship of thioredoxin with tumor size, Child-Pugh class and tumor stage were evaluated. There was a significant correlation between thioredoxin concentrations and tumor size, Child-Pugh class or tumor stage $(r=0.311, P<0.0001 ; r=0.377$, $P<0.001 ; r=0.442, P<0.0001$; respectively). The level of thioredoxin tended to increase as liver disease progressed from Child-Pugh class A to $\mathrm{C}$ as well as tumor stage from I to IV. For comparison, AFP values of different tumor size or differentiation status or liver function were also analyzed. There was no significantly correlation were obtained. In addition, there was a weak but significant positive correlation between thioredoxin and Hs-CRP $(r=0.201, P<0.001)$. Statistical analysis here revealed no influence of age, sex, infection time, etiology, ALT, AST, total bilirubin, prothrombin time and AFP on thioredoxin in HCC patients $(P>0.05$, respectively). Similarly results were obtained in the validation cohort. There was also a significant positive correlation between THIOREDOXIN and Hs-CRP $(r=0.209, P<0.001)$.

In univariate logistic regression analysis, thioredoxin as a continuous variable was associated with an increased risk of HCC with an unadjusted OR of 1.39 (95\% CI, $1.19-1.72 ; P<0.001)$ when controls with LC were included. After adjusting for all other possible covariates, thioredoxin remained can be seen as an independent diagnosis marker of HCC with an adjusted OR of 1.21 (95\% CI, 1.13-1.32; $P<0.0001)$. Similarly, thioredoxin as a continuous variable was associated with an increased risk of $\mathrm{HCC}$ with an unadjusted OR of 1.45 (95\% CI, $1.22-1.91 ; P<0.001)$ when controls with LC and CLD were included. After adjusting for all other possible 
Table 1: Baseline characteristics of the HCC and control cases in training cohort

\begin{tabular}{|c|c|c|c|c|}
\hline & HCC & $\mathbf{L C}$ & CLD & Normal cases \\
\hline No. & 180 & 120 & 120 & 100 \\
\hline Age (IQR, years) & $56(45-64)$ & $56(44-64)$ & $55(45-63)$ & $56(45-64)$ \\
\hline Males (\%) & 52.8 & 53.3 & 53.3 & 53.0 \\
\hline Infection time(IQR, years) & $30(22-39)$ & $28(19-32)$ & $25(18-31)^{\mathrm{b}}$ & - \\
\hline \multicolumn{5}{|l|}{ Etiology $(\mathrm{N})$} \\
\hline HBV & 150 & 95 & 96 & - \\
\hline $\mathrm{HCV}$ & 33 & 27 & 25 & - \\
\hline Combination $(\mathrm{HBV}+\mathrm{HCV})$ & 5 & 3 & 2 & - \\
\hline Alcohol & 2 & 1 & 1 & - \\
\hline HBV copies $>10^{3}(\mathrm{~N})$ & 134 & $45^{\mathrm{b}}$ & $32^{\mathrm{b}}$ & - \\
\hline Tumor size (IQR, cm) & $6.2(2.5-19.5)$ & - & - & - \\
\hline Presence of PVT (\%) & $55(30.6)$ & - & - & - \\
\hline Presence of metastasis (\%) & $33(18.3)$ & - & - & - \\
\hline \multicolumn{5}{|l|}{ Child-Pugh (N) } \\
\hline Class A & 100 & 78 & - & - \\
\hline Class B & 60 & 32 & - & - \\
\hline Class C & 20 & 10 & - & - \\
\hline \multicolumn{5}{|l|}{$\operatorname{Grading}(\mathrm{N})$} \\
\hline G1 & 113 & - & - & - \\
\hline $\mathrm{G} 2 / 3$ & 67 & - & - & - \\
\hline \multicolumn{5}{|l|}{ Tumour stage ${ }^{\mathrm{a}}$} \\
\hline I & 40 & - & - & - \\
\hline II & 70 & - & - & - \\
\hline III & 62 & - & - & - \\
\hline IV & 8 & - & - & - \\
\hline \multicolumn{5}{|l|}{ No. of nodules $(\mathrm{N})$} \\
\hline 1 & 115 & - & - & - \\
\hline$>1$ & 65 & - & - & - \\
\hline \multicolumn{5}{|l|}{ Nodule size $(\mathrm{N})$} \\
\hline$\leq 2 \mathrm{~cm}$ & 38 & - & - & - \\
\hline$>2 \mathrm{~cm}$ & 142 & - & - & - \\
\hline \multicolumn{5}{|l|}{ Laboratory findings(IQR) } \\
\hline Platelet counts $\left(\times 10^{3} / \mathrm{mm} 3\right)$ & $152(124-189)$ & $163(133-199)$ & $165(132-205)$ & $194(167-245)^{b}$ \\
\hline ALT (U/L) & $115(25-282)$ & $136(35-302)$ & $127(32-300)$ & $27(19-32)^{\mathrm{b}}$ \\
\hline AST(U/L) & $120(36-316)$ & $147(42-330)$ & $155(50-387)$ & $29(20-33)^{\mathrm{b}}$ \\
\hline Total bilirubin $(\mathrm{mg} / \mathrm{dL})$ & $0.92(0.78-1.42)$ & $1.02(0.89-1.55)$ & $1.23(1.01-1.67)$ & $0.55(0.32-0.87)^{\mathrm{b}}$ \\
\hline Albumin $(\mathrm{g} / \mathrm{L})$ & $35.2(32.8-40.4)$ & $36.1(33.2-41.4)$ & $37.0(35.2-43.4)$ & $43.2(39.4-47.6)^{b}$ \\
\hline
\end{tabular}

(Continued) 


\begin{tabular}{|l|c|c|c|c|}
\hline \multicolumn{2}{c}{ HCC } & LC & CLD & Normal cases \\
\hline Prothrombin time (\%) & $14.6(11.2-18.5)$ & $14.2(10.8-18.2)$ & $13.5(10.2-18.0)$ & $12.2(11.5-13.4)^{\mathrm{b}}$ \\
\hline HS-CRP $(\mathrm{mg} / \mathrm{dl})$ & $0.99(0.45-1.77)$ & $0.66(0.35-0.89)^{\mathrm{b}}$ & $0.59(0.37-0.85)^{\mathrm{b}}$ & $0.28(0.11-0.35)^{\mathrm{b}}$ \\
\hline AFP $(\mathrm{ng} / \mathrm{ml})$ & $142(18-548)$ & $15.4(8.7-30.2)^{\mathrm{b}}$ & $13.6(6.8-24.4)^{\mathrm{b}}$ & $6.6(4.0-9.2)^{\mathrm{b}}$ \\
\hline TRX $(\mathrm{ng} / \mathrm{ml})$ & $45.1(28.2-56.0)$ & $9.0(6.1-11.9)^{\mathrm{b}}$ & $8.1(5.0-10.2)^{\mathrm{b}}$ & $7.5(6.0-9.2)^{\mathrm{b}}$ \\
\hline
\end{tabular}

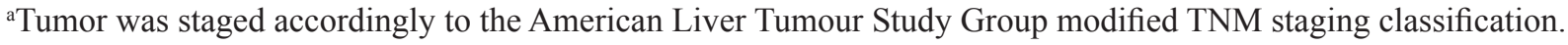
${ }^{\mathrm{b}} p$ value $<0.05$, compare with HCC group. HBV, hepatitis B virus; HCV, hepatitis C virus; ALT, alanine aminotransferase; PVT, portal vein thrombosis; AFP, $\alpha$-fetoprotein; CLD, chronic liver diseases; HCC, Hepatocellular carcinoma; LC, liver cirrhosis; Hs-CRP, High-sensitivity- C-reactive protein; TRX, thioredoxin.
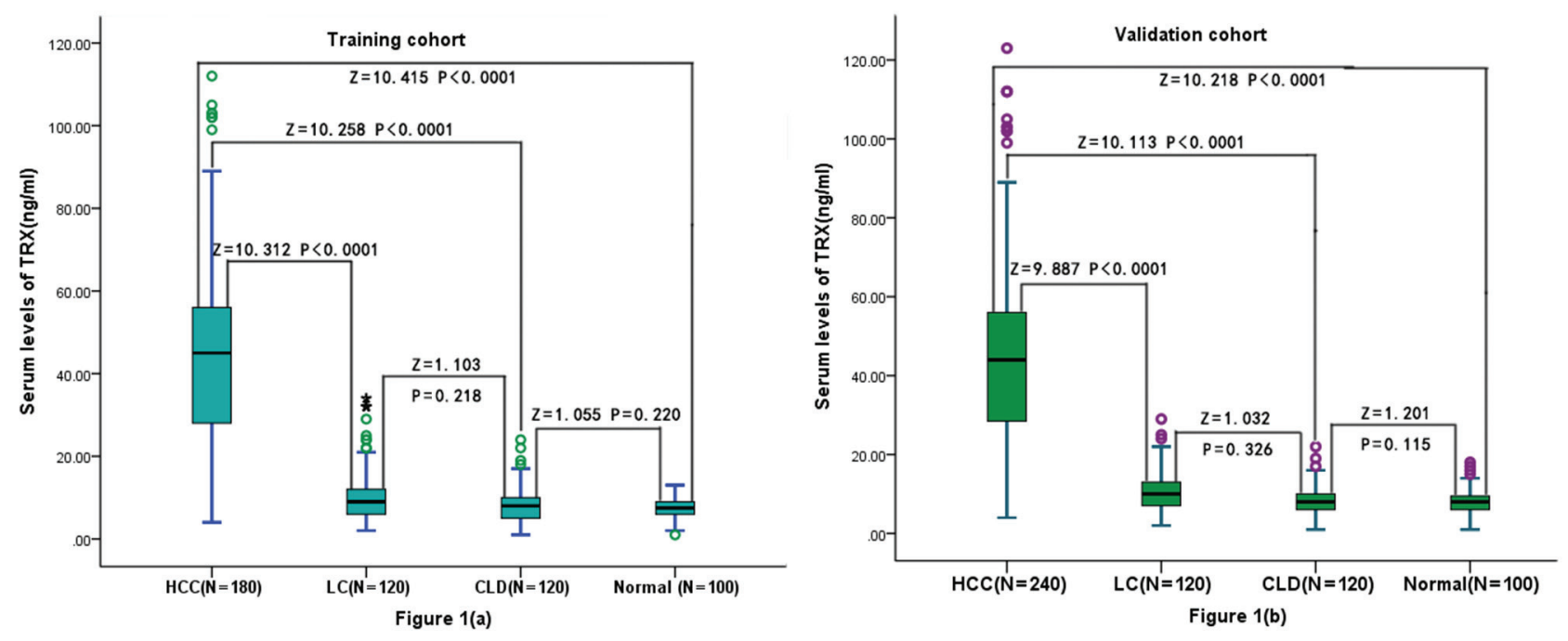

Figure 1: Box plot for serum TRX values in the studied groups. (a) Box plot for serum TRX values in the training cohort and controls; (b) Box plot for serum TRX values in the validation cohort and controls. The box indicates the 25 th and 75 th percentile of the data, and the middle line, the median. A line extends from the minimum to the maximum value, excluding outliers that are displayed as separate points. $\mathrm{CLD}=$ chronic liver diseases; $\mathrm{LC}=$ liver cirrhosis; $\mathrm{HCC}=$ hepatocellular carcinoma; $\mathrm{TRX}=$ thioredoxin.

covariates, thioredoxin remained can be seen as an independent diagnosis marker of HCC with an adjusted OR of 1.25 (95\% CI, $1.16-1.35 ; P<0.0001)$. This relationship was confirmed in the dose-response model (Table 2). When all the HCC patients and controls were included, thioredoxin still was associated with an increased risk of $\mathrm{HCC}$ with an unadjusted OR of 1.56 (95\% CI, 1.25 $-1.99 ; P<0.001)$. Again, after adjusting for all other possible covariates, thioredoxin remained can be seen as an independent diagnosis marker of $\mathrm{HCC}$ with an adjusted OR of 1.33 (95\% CI, 1.21-1.54; $P<0.001$; Table 2.)

\section{Thioredoxin has higher sensitivity and specificity than AFP in diagnosis of $\mathrm{HCC}$}

A ROC curve was plotted to define the optimal cutoff values, and to identify the sensitivity and specificity of serum thioredoxin and AFP levels in differentiating patients with $\mathrm{HCC}$ versus all other conditions. Based on the ROC curve, the optimal cutoff value of serum thioredoxin levels as an indicator for auxiliary diagnosis of HCC was projected to be $20.5 \mathrm{ng} / \mathrm{mL}$, which yielded a sensitivity of $84.3 \%$ and a specificity of $91.8 \%$, with the area under the curve at $0.946(95 \% \mathrm{CI}, 0.923-0.969)$; Table 3 and Figure 2a. The optimum cutoff value for AFP was $18.5 \mathrm{ng} /$ mL (AUC 0.878, 95\% CI: 0.841-0.914, sensitivity 78.4\%, specificity of $81.3 \%$ ). As the sensitivity and specificity were similar to those for the recommended clinical cutoff of $20 \mathrm{ng} / \mathrm{mL}$ ( $80.1 \%$ and $85.9 \%$, respectively; $P=0.231$ ), we chose $20 \mathrm{ng} / \mathrm{mL}$ as the cutoff value for AFP in this study. Predictive values for thioredoxin and AFP in the diagnosis of HCC are shown in Table 3. Thioredoxin had a better AUROC compared with AFP $(P<0.001)$, indicating both a higher sensitivity and specificity of thioredoxin compared with AFP in the diagnosis of HCC (Figure 2a). When HCC patients were compared with CLD and LC patients, the AUC for thioredoxin was also larger than that for AFP (0.901, 0.875-0.923 vs. 0.842, 0.821-0.889, $P=0.002$; Table 3). Similarly, when HCC patients were compared with LC patients, the AUC for THIOREDOXIN was also larger than that for $\operatorname{AFP}(0.874,0.843-0.901$ vs. $0.824,0.801-0.853, P=0.004)$. 
Table 2: Univariate and Multivariate logistic regression analysis for risk of $\mathrm{HCC}$

\begin{tabular}{|c|c|c|c|c|c|c|}
\hline \multirow[t]{2}{*}{ Parameter } & \multicolumn{3}{|c|}{ Univariate Analysis } & \multicolumn{3}{|c|}{ Multivariate Analysis } \\
\hline & $\mathbf{O R}^{\mathbf{a}}$ & $95 \% C^{a}$ & $P$ & $\mathbf{O R}^{\mathbf{a}}$ & $95 \% \mathrm{CI}^{\mathrm{a}}$ & $P$ \\
\hline \multicolumn{7}{|l|}{ Training cohort } \\
\hline \multicolumn{7}{|c|}{ Predictor: HCC VS LC and CLD } \\
\hline Age & 1.25 & $1.08-1.77$ & 0.003 & 1.20 & $1.04-1.64$ & 0.004 \\
\hline Sex & 1.08 & $0.87-1.45$ & 0.132 & - & & \\
\hline Hs-CRP & 1.17 & $1.08-1.27$ & 0.009 & 1.11 & $1.01-1.13$ & 0.012 \\
\hline Family history & 13.12 & $3.12-97.34$ & $<0.001$ & 10.14 & $2.11-89.45$ & 0.003 \\
\hline HBV copies $>10^{3}$ & 6.32 & $2.44-18.34$ & $<0.001$ & 5.55 & $2.01-15.02$ & $<0.001$ \\
\hline $\mathrm{AFP}>20 \mathrm{ng} / \mathrm{ml}$ & 4.76 & $2.01-11.32$ & $<0.001$ & 4.45 & $1.84-10.18$ & $<0.001$ \\
\hline $\mathrm{ALT}>40 \mathrm{U} / \mathrm{L}$ & 2.11 & $1.35-3.65$ & 0.009 & 1.91 & $1.24-3.19$ & 0.011 \\
\hline Albumin $<4.0 \mathrm{~g} / \mathrm{dL}$ & 1.78 & $1.09-2.04$ & 0.022 & 1.45 & $1.03-2.03$ & 0.231 \\
\hline $\mathrm{TRX}^{\mathrm{a}}$ & 1.45 & $1.22-1.91$ & $<0.001$ & 1.25 & $1.16-1.35$ & $<0.001$ \\
\hline $\mathrm{TRX}(>20.5 \mathrm{ng} / \mathrm{mL})$ & 13.22 & $2.99-87.32$ & $<0.001$ & 7.03 & $2.04-15.87$ & $<0.001$ \\
\hline \multicolumn{7}{|c|}{ Predictor: HCC VS LC, CLD and normal } \\
\hline Age & 1.28 & $1.06-1.59$ & $<0.001$ & 1.24 & $1.05-1.54$ & 0.001 \\
\hline Sex & 1.14 & $0.98-2.08$ & 0.432 & - & & \\
\hline Hs-CRP & 1.19 & $1.08-1.45$ & $<0.001$ & 1.15 & $1.04-1.56$ & 0.009 \\
\hline Family history & 13.65 & $3.31-99.87$ & $<0.001$ & 11.34 & $1.95-93.87$ & $<0.001$ \\
\hline HBV copies $>10^{3}$ & 4.98 & $2.04-12.43$ & $<0.001$ & 4.88 & $1.99-11.78$ & $<0.001$ \\
\hline $\mathrm{AFP}>20 \mathrm{ng} / \mathrm{ml}$ & 5.99 & $2.04-15.32$ & $<0.001$ & 5.15 & $1.77-14.15$ & $<0.001$ \\
\hline $\mathrm{ALT}>40 \mathrm{U} / \mathrm{L}$ & 2.43 & $1.65-3.65$ & 0.001 & 2.22 & $1.41-3.48$ & 0.003 \\
\hline Albumin $<4.0 \mathrm{~g} / \mathrm{dL}$ & 1.98 & $1.17-2.43$ & 0.015 & 1.76 & $1.02-3.01$ & 0.076 \\
\hline $\mathrm{TRX}^{\mathrm{a}}$ & 1.56 & $1.25-1.99$ & $<0.001$ & 1.33 & $1.25-1.99$ & $<0.001$ \\
\hline $\mathrm{TRX}(>20.5 \mathrm{ng} / \mathrm{mL})$ & 14.43 & $2.76-93.21$ & $<0.001$ & 8.12 & $1.98-18.32$ & $<0.001$ \\
\hline \multicolumn{7}{|l|}{ Validation cohort } \\
\hline \multicolumn{7}{|c|}{ Predictor: HCC VS LC and CLD } \\
\hline Age & 1.24 & $1.08-1.66$ & 0.001 & 1.18 & $1.03-1.50$ & 0.005 \\
\hline Sex & 1.12 & $0.85-1.48$ & 0.176 & & & \\
\hline Hs-CRP & 1.19 & $1.09-1.26$ & 0.008 & 1.08 & $1.02-1.24$ & 0.021 \\
\hline Family history & 12.76 & $3.04-95.32$ & $<0.001$ & 11.67 & $1.89-94.23$ & 0.002 \\
\hline HBV copies $>10^{3}$ & 6.38 & $2.40-18.28$ & $<0.001$ & 5.77 & $1.89-17.12$ & $<0.001$ \\
\hline $\mathrm{AFP}>20 \mathrm{ng} / \mathrm{ml}$ & 4.54 & $2.03-11.43$ & $<0.001$ & 4.34 & $1.78-10.21$ & $<0.001$ \\
\hline $\mathrm{ALT}>40 \mathrm{U} / \mathrm{L}$ & 2.05 & $1.32-3.60$ & 0.008 & 1.87 & $1.25-3.02$ & 0.018 \\
\hline Albumin $<4.0 \mathrm{~g} / \mathrm{dL}$ & 1.72 & $1.07-2.11$ & 0.021 & 1.45 & $0.98-2.09$ & 0.062 \\
\hline $\mathrm{TRX}^{\mathrm{a}}$ & 1.45 & $1.22-1.91$ & $<0.001$ & 1.24 & $1.21-1.54$ & $<0.001$ \\
\hline $\mathrm{TRX}(>20.5 \mathrm{ng} / \mathrm{mL})$ & 13.22 & $2.99-87.32$ & $<0.001$ & 7.22 & $2.09-15.09$ & $<0.001$ \\
\hline \multicolumn{7}{|c|}{ Predictor: HCC VS LC, CLD and normal } \\
\hline Age & 1.29 & $1.06-1.65$ & $<0.001$ & 1.22 & $1.11-1.35$ & $<0.001$ \\
\hline Sex & 1.17 & $0.95-2.11$ & 0.409 & & & \\
\hline Hs-CRP & 1.17 & $1.07-1.36$ & $<0.001$ & 1.13 & $1.04-1.53$ & 0.008 \\
\hline
\end{tabular}




\begin{tabular}{|c|c|c|c|c|c|c|}
\hline \multirow[t]{2}{*}{ Parameter } & \multicolumn{3}{|c|}{ Univariate Analysis } & \multicolumn{3}{|c|}{ Multivariate Analysis } \\
\hline & $\mathrm{OR}^{\mathrm{a}}$ & $95 \% \mathrm{CI}^{\mathrm{a}}$ & $P$ & $\mathbf{O R}^{\mathbf{a}}$ & $95 \% \mathrm{CI}^{\mathrm{a}}$ & $P$ \\
\hline Family history & 12.09 & $3.11-94.23$ & $<0.001$ & 10.99 & $1.98-89.04$ & $<0.001$ \\
\hline HBV copies $>10^{3}$ & 5.05 & $2.07-12.65$ & $<0.001$ & 4.75 & $2.03-10.86$ & $<0.001$ \\
\hline $\mathrm{AFP}>20 \mathrm{ng} / \mathrm{ml}$ & 6.04 & $2.11-14.98$ & $<0.001$ & 5.09 & $1.82-13.89$ & $<0.001$ \\
\hline $\mathrm{ALT}>40 \mathrm{U} / \mathrm{L}$ & 2.56 & $1.67-3.54$ & $<0.001$ & 2.18 & $1.37-3.14$ & 0.003 \\
\hline Albumin $<4.0 \mathrm{~g} / \mathrm{dL}$ & 2.03 & $1.22-3.19$ & 0.032 & 1.54 & $1.06-2.87$ & 0.076 \\
\hline $\mathrm{TRX}^{\mathrm{a}}$ & 1.57 & $1.23-2.02$ & $<0.001$ & 1.36 & $1.21-1.86$ & $<0.001$ \\
\hline $\mathrm{TRX}(>20.5 \mathrm{ng} / \mathrm{mL})$ & 15.04 & $2.06-88.76$ & $<0.001$ & 8.09 & $1.93-17.65$ & $<0.001$ \\
\hline
\end{tabular}

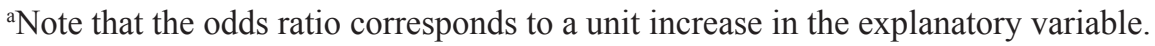

OR, odds ratio; CI, confidence interval; HCC, Hepatocellular carcinoma; CLD, chronic liver diseases; LC, liver cirrhosis; Hs-CRP, High-sensitivity- C-reactive protein; HBV, hepatitis B virus; ALT, alanine aminotransferase; AFP, $\alpha$-fetoprotein; TRX, thioredoxin.

Using the optimal cut-offs derived from the ROC curve, thioredoxin was positive in 40 of $55(72.7 \%)$ patients with an AFP $<20 \mathrm{ng} / \mathrm{ml}$. In contrast, AFP was positive in 14 of $34(41.2 \%)$ patients with a thioredoxin $<20.5 \mathrm{ng} / \mathrm{mL}$. Combined model (THIOREDOXIN and AFP) increased the sensitivity for HCC to $88.7 \%$, with a specificity of $92.2 \%$, and the AUROC was 0.98 (95\% CI: 0.97-0.99; Figure 2a). Combined model showed a significantly greater discriminatory ability as compared with those markers alone (Table 3 ). In the assessment of validation cohort, serum thioredoxin also had greater AUC, sensitivity, and specificity values than did AFP in patients with HCC compared with control cases (Figure $2 \mathrm{~b}$ and Table 3 ). Combined model was better than those alone. Based on the ROC curve, the optimal cutoff value of serum thioredoxin levels as an indicator for auxiliary diagnosis of HCC was projected to be $20.9 \mathrm{ng} / \mathrm{mL}$, which yielded a sensitivity of $84.1 \%$ and a specificity of $91.6 \%$, with the area under the curve at $0.941(95 \% \mathrm{CI}, 0.918-0.963)$. The optimum cutoff value for AFP was $18.4 \mathrm{ng} / \mathrm{mL}$ (AUC $0.880,95 \% \mathrm{CI}$ : $0.848-0.912$, sensitivity $78.6 \%$, specificity of $81.6 \%$ ). Thus, the diagnostic cut-off values of serum thioredoxin and AFP were also chosen $20.5 \mathrm{ng} / \mathrm{mL}$ and $20 \mathrm{ng} / \mathrm{mL}$, respectively.

In the training cohort, $38(21.1 \%)$ of 180 patients with HCC had very early disease. Levels of thioredoxin in serum were significantly higher in these patients than those in all controls [29.2(IQR, 20.1-37.6) vs. 8.2 (5.310.6) ng/ml; $P<0.0001]$. Serum thioredoxin improved differential diagnosis of very early HCC from all controls and from controls at risk of HCC, compared with AFP (Figure 2c, Table 3). When HCC patients were compared with CLD and LC patients, the AUC for thioredoxin was larger than that for AFP $(0.854,0.812-0.903$ vs. $0.729,0.684-0.838, P<0.0001$; Table 3). Again, when HCC patients were compared with LC patients, the AUC for thioredoxin was also larger than that for AFP
(0.801, 0.767-0.845 vs. $0.703,0.665-0.763, P=0.003)$. Furthermore, a higher proportion of patients with very early HCC had positive results for thioredoxin than for AFP (73.7\% VS.31.6\%; $P<0.0001)$. Among AFPnegative patients with very early HCC, $18(69.2 \%)$ of 26 had positive thioredoxin results. With use of the 20.5 $\mathrm{ng} / \mathrm{mL}$ threshold for thioredoxin, we observed similar results in the validation cohort to those in the test cohort. Serum thioredoxin also had greater AUC, sensitivity, and specificity values than did AFP in patients with very early HCC compared with control cases (Figure 2d, Table 3). Combined model was better than those alone.

Interestingly, in training cohort, 132 out of the 180 HCC patients were with AST and/or ALT elevation ( $>40$ $\mathrm{U} / \mathrm{L}$ ). When HCC patients were compared with CLD and LC patients, the AUC for thioredoxin was larger than that for AFP $(0.832,0.799-0.884 v s .0 .732,0.674-0.815, P<$ $0.0001)$. Again, when HCC patients were compared with LC patients, the AUC for thioredoxin was also larger than that for AFP $(0.805,0.769-0.842$ vs. 0.704, 0.661-0.763, $P=0.002$ ). Furthermore, combined model (thioredoxin and AFP) showed a significantly greater discriminatory ability as compared with those markers alone.

\section{DISCUSSION}

HCC represents an extremely poor prognostic cancer that remains one of the most common and aggressive human malignancies worldwide. The early diagnosis of HCC use of serological markers is of great clinical desirable and the improved prognosis of HCC if the patients could get surgical treatment early [1]. Up to now, AFP has mainly been used in clinic for diagnosis of primary HCC; however, its sensitivity and specificity are not satisfying [23], novel biomarkers for early HCC diagnosis are greatly needed. This study was performed in order to discover valuable non-invasive serum biomarkers which could be obtained without any 


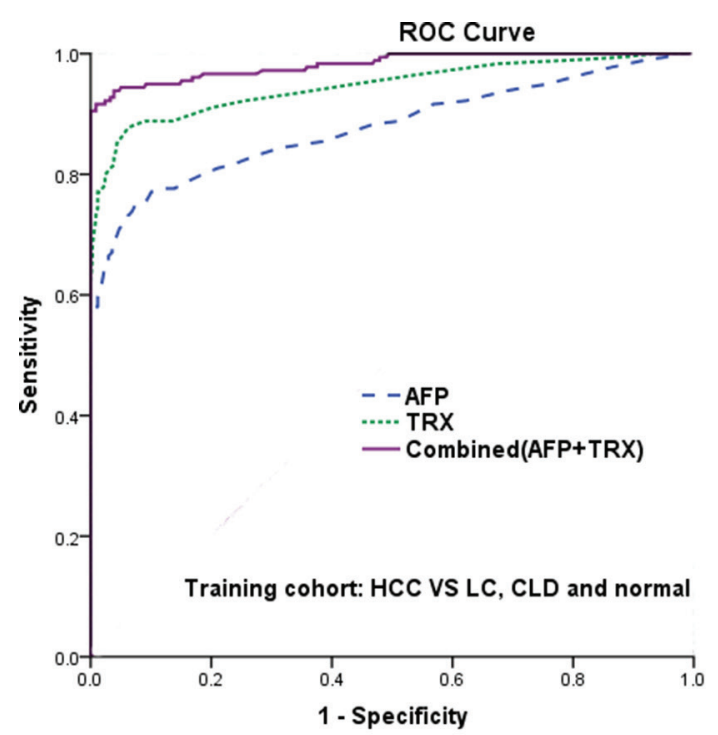

Figure 2(a)

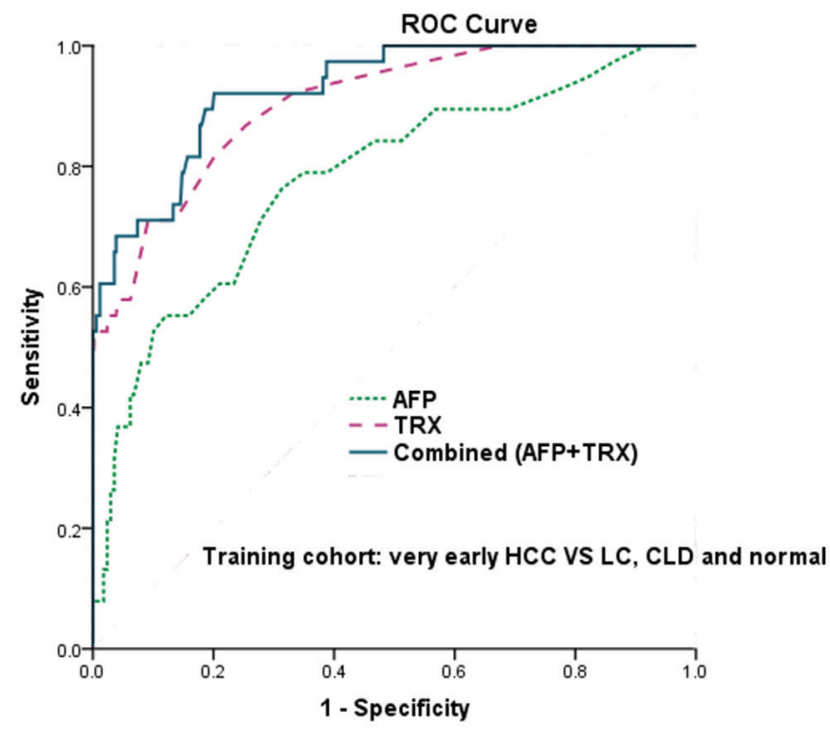

Figure 2(c)

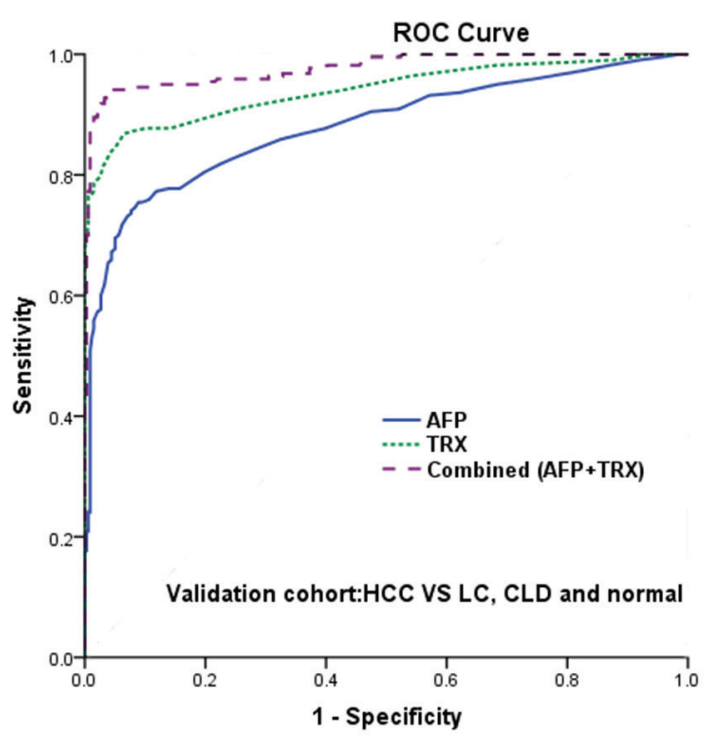

Figure 2(b)

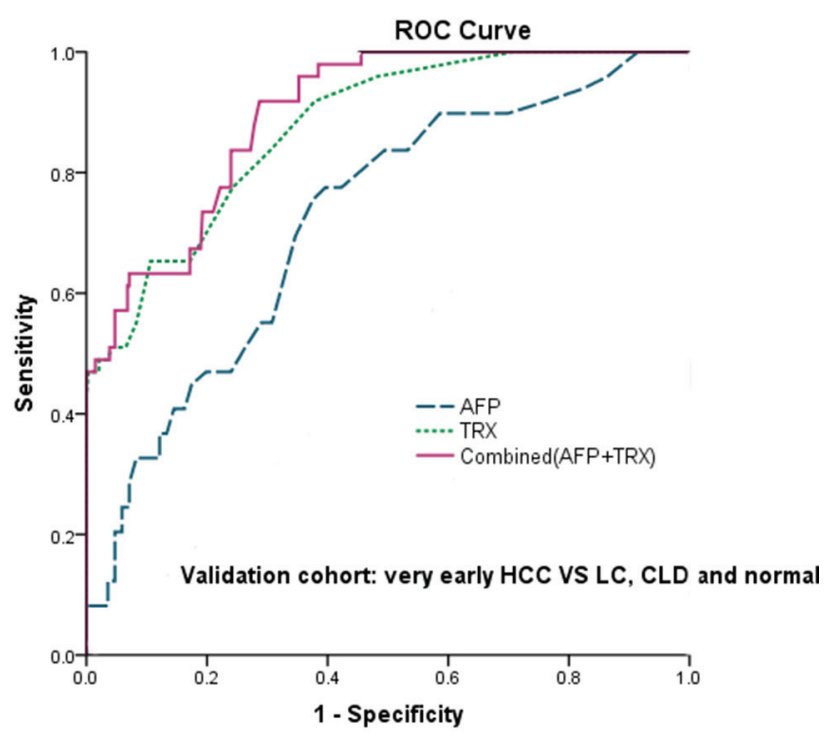

Figure 2(d)

Figure 2: Diagnostic performance of serum TRX and AFP as diagnostic markers for HCC and very early HCC evaluated by the ROC curve. (a) ROC curve for TRX, AFP, or both for all patients with HCC versus all controls in the training cohort. (b) ROC curve for TRX, AFP, or both for all patients with HCC versus all controls in the validation cohort. (c) ROC curve for TRX, AFP, or both for patients with very early HCC versus all controls in the training cohort. (d) ROC curve for TRX, AFP, or both for patients with very early $\mathrm{HCC}$ versus all controls in the validation cohort. $\mathrm{ROC}=$ receiver operating characteristics. $\mathrm{CLD}=$ chronic liver diseases. $\mathrm{LC}=$ liver cirrhosis. $\mathrm{HCC}=$ hepatocellular carcinoma; TRX $=$ thioredoxin.

invasive manipulations such as biopsy for the earliest diagnosis of HCC.

Thioredoxin is involved in various biological activities, including regulating cancer cell growth. These biological activities highlight the importance of redox processes in the pathophysiology of cancer. Park et al. [24] suggested that serum thioredoxin 1 is useful for the early diagnosis of ovarian cancer. We firstly suggested that serum thioredoxin may be a novel marker of HCC in Chinese sample. Similarly, Miyazaki et al. [22] suggesting that measurement of serum of thioredoxin might be a useful clinical parameter when HCC is suspected. However, in our study, the ROC curve comparing all the HCC patients showed that thioredoxin was superior to AFP in diagnosing HCC with an AUROC of 0.95 (95\% CI: $0.92-0.97$ ) and a sensitivity of $84.3 \%$, and a specificity of 91.8\% (AFP: 0.88). Our findings suggested an advantage of thioredoxin over AFP as a serum marker for detection of HCC, especially for patients with very early HCC and AFP-negative status. The combined measurement of thioredoxin and AFP can further increase the sensitivity for the detection of HCC. In addition, the level of thioredoxin 
Table 3: Results for measurement of serum THIOREDOXIN, AFP, or both,* in the diagnosis of $\mathrm{HCC}$

\begin{tabular}{|c|c|c|c|c|c|c|c|c|}
\hline & \multicolumn{4}{|c|}{ Training cohort } & \multicolumn{4}{|c|}{ Validation cohort } \\
\hline & AUC & $95 \%$ CI & sensitivity & specificity & AUC & $95 \%$ & sensitivity & specificity \\
\hline \multicolumn{9}{|c|}{ HCC vs LC, CLD and normal } \\
\hline TRX & 0.946 & $0.923-0.969$ & $84.3 \%$ & $91.8 \%$ & 0.941 & $0.918-0.963$ & $84.1 \%$ & $91.6 \%$ \\
\hline AFP & 0.878 & $0.841-0.914$ & $78.4 \%$ & $81.3 \%$ & 0.880 & $0.848-0.912$ & $78.6 \%$ & $81.6 \%$ \\
\hline $\begin{array}{l}\text { Combined (TRX + } \\
\text { ALP) }\end{array}$ & 0.982 & $0.970-0.994$ & $88.7 \%$ & $92.2 \%$ & 0.978 & $0.967-0.990$ & $88.7 \%$ & $92.7 \%$ \\
\hline \multicolumn{9}{|l|}{$\mathrm{HCC} v s \mathrm{LC}$ and CLD } \\
\hline TRX & 0.901 & $0.875-0.923$ & $78.2 \%$ & $87.5 \%$ & 0.906 & $0.870-0.925$ & $78.7 \%$ & $87.8 \%$ \\
\hline AFP & 0.842 & $0.821-0.889$ & $74.2 \%$ & $79.2 \%$ & 0.840 & $0.820-0.884$ & $74.0 \%$ & $79.1 \%$ \\
\hline $\begin{array}{l}\text { Combined (TRX + } \\
\text { ALP) }\end{array}$ & 0.942 & $0.922-0.967$ & $86.4 \%$ & $89.1 \%$ & 0.941 & $0.921-0.967$ & $86.6 \%$ & $89.4 \%$ \\
\hline \multicolumn{9}{|c|}{ Very early HCC vs LC, CLD and normal } \\
\hline TRX & 0.854 & $0.825-0.925$ & $74.9 \%$ & $86.7 \%$ & 0.901 & $0.854-0.948$ & $75.2 \%$ & $88.9 \%$ \\
\hline AFP & 0.720 & $0.646-0.794$ & $68.6 \%$ & $75.2 \%$ & 0.769 & $0.687-0.856$ & $70.1 \%$ & $79.4 \%$ \\
\hline $\begin{array}{l}\text { Combined (TRX + } \\
\text { ALP) }\end{array}$ & 0.889 & $0.866-0.913$ & $81.3 \%$ & $93.4 \%$ & 0.917 & $0.856-0.956$ & $83.1 \%$ & $94.0 \%$ \\
\hline \multicolumn{9}{|c|}{ Very early HCC $v s$ LC and CLD } \\
\hline TRX & 0.844 & $0.812-0.903$ & $74.5 \%$ & $79.6 \%$ & 0.847 & $0.823-0.886$ & $74.8 \%$ & $80.1 \%$ \\
\hline AFP & 0.729 & $0.684-0.838$ & $70.1 \%$ & $69.8 \%$ & 0.727 & $0.681-0.840$ & $71.2 \%$ & $77.5 \%$ \\
\hline $\begin{array}{l}\text { Combined (TRX + } \\
\text { ALP) }\end{array}$ & 0.875 & $0.842-0.920$ & $81.6 \%$ & $87.4 \%$ & 0.870 & $0.839-0.915$ & $80.5 \%$ & $86.9 \%$ \\
\hline
\end{tabular}

*The diagnostic cutoff values of serum THIOREDOXIN and AFP were $20.5 \mathrm{ng} / \mathrm{mL}$ and $20 \mathrm{ng} / \mathrm{mL}$, respectively.

AUC: area under curve; CI, confidence interval; HCC, Hepatocellular carcinoma; CLD, chronic liver diseases; LC, liver cirrhosis; AFP, $\alpha$-fetoprotein; TRX, thioredoxin.

tended to increase as liver disease progressed from ChildPugh class A to $\mathrm{C}$ as well as tumor stage from I to IV. We have found that the elevation of serum THIOREDOXIN was significantly higher in patients with HCC as compare with cirrhosis. Therefore, serum thioredoxin can be used to monitor disease progression in patients with HCC.

Although the diagnostic role of serum AFP in advanced HCC is well recognized, at least one third of small HCCs and up to $40 \%$ of advanced HCC will be missed unless other diagnostic tools are used [25]. Similarly, in our study, $30.6 \%(55 / 180)$ of the HCC patients and $68.4 \%(26 / 38)$ of the very-early HCC patients were AFP-negative $(<20 \mathrm{ng} / \mathrm{mL})$. In addition, AFP concentrations are raised in $11-58 \%$ of patients with chronic hepatitis or cirrhosis in the absence of HCC [26], which was supported by our results. These shortcomings have motivated many investigators to search for other better tumor markers for HCC.

In previous studies, several new biomarkers, such as Golgi protein-73 [27], glypican 3 [9], nidogen-2 [28], heat shock protein 70 [29], and glutamine synthetase [27], ATP-dependent DNA helicase II [3], Des-c-carboxy prothrombin (DCP) [30], squamous cell carcinoma antigen (SCCA) [31], miR-24-3p [32] and miR-483-5p [33] have been investigated for their diagnostic performance and potential clinical application. However, as sensitivity and specificity values of these serological markers were low, they proved to be inadequate for HCC screening purposes, even when combined [34-35]. Few markers have been introduced into the clinic over, mainly because they have not met the following criteria: specific overexpression in cancer cells but not in corresponding normal cells; secreted proteins that can be easily detected in serum; and rare expression in human adult normal tissues except in embryonic tissues [26]. Thioredoxin meets these criteria. Therefore, this protein might have potential as a cancerspecific serum biomarker for various human cancers, including HCC. In this study, we found that thioredoxin was better than AFP for the diagnosis of HCC and very early HCC. In addition, measurement of thioredoxin in 
serum can help to make a differential diagnosis of HCC in patients in high-risk populations. Further validation studies are needed to confirm the role of thioredoxin in the early detection of HCC.

Whether higher circulating thioredoxin level is an accelerator or only is a marker of HCC remains uncertain. It is important to discuss whether thioredoxin in HCC patients have pathological roles or just was as indicator of oxidative stress or inflammation. Serum thioredoxin levels have been reported to decline significantly after surgical removal of HCC, and may be produced and secreted by HCC cells [36]. When thioredoxin levels are elevated there is increased cell growth and resistance to the normal mechanism of programmed cell death. An increase in thioredoxin levels seen in many human primary cancers compared to normal tissue appears to contribute to increased cancer cell growth and resistance to chemotherapy [37]. Thioredoxin stimulates the growth of a variety of tumor cell lines [38]. Mechanisms by which thioredoxin increases cell growth include an increased supply of reducing equivalents for DNA synthesis [39], reduce hydrogen peroxide [40] and to function as an electron donor to human plasma glutathione peroxidase [41], activation of transcription factors that regulate cell growth [37], and an increase in the sensitivity of cells to other cytokines and growth factors [42]. Because of its role in stimulating cancer cell growth and as an inhibitor of apoptosis, thioredoxin offers a target for the development of drugs to treat and prevent cancer. Importantly, it was previously reported that serum levels of thioredoxin, which is a stress-induced protein, increase relative to the degree of hepatic fibrosis, and that high serum concentrations of thioredoxin may indicate advanced hepatic fibrosis [43]. Correspondingly, Sumida et al. [36] suggested that thioredoxin may therefore be responsible for the pathological mechanism of HCV-related hepatic fibrogenesis, and Tamai et al. [44] reported that serum thioredoxin levels were potential clinical biomarkers that predict patient prognosis in HCV-related HCC. Thus, thioredoxin might play important role in the process of $\mathrm{HCC}$ rather than just was a diagnosis marker.

\section{Strengths and limitations}

There have been a few papers in the literature linking thioredoxin and HCC [22, 44], fewer linking very early HCC and AFP-negative status and, as far as I could find, none in an ethnic Chinese sample. As such this manuscript adds significantly to the literature, especially as HCC of ethnic Chinese origin make up such a high proportion of the world and the results are likely to be generalizable to a non-Chinese population. In addition, this study included test and validation cohort which came from different cities, and we were able to control for multiple variables.

Several limitations of this study should be noted. First, in the present study, the classical determination of thioredoxin by ELISA method is widely used, which is considered 'gold standard'. However, it is widely known that human serum contains immunoglobulins that affect the results of immunoassays by binding to reagent antibodies used in the assay. HAb interference can frequently cause a false positive signal [45]. Second, without serial measurement of the circulating thioredoxin levels, this study yielded no data regarding when and how the change of serum levels in these patients. In addition, thioredoxin measurements were performed after the $\mathrm{HCC}$ and may not accurately reflect pre-HCC exposure. Third, we measured only thioredoxin, which is a single antioxidant defense parameter. Effective antioxidant protection is provided by the cooperative and sequential actions of several antioxidant enzymes, and non-enzyme antioxidant molecules. So we could not determine the association of those factors with thioredoxin levels and HCC. Fourth, we measured thioredoxin in serum, not in histologic specimen. It is still uncertain whether peripheral thioredoxin levels reflect similar changes in the liver tissue. However, we did not get relevant information in this study. The relationship between peripheral and tissue thioredoxin levels warrants further investigation. Lastly limitation is the lack of outcome data. This study yielded no data regarding whether treatment can change serum levels in these patients. In addition, we did not obtain the information about antiviral therapy against HBV and/ or HCV. So we could not determine the association of antiviral therapy with thioredoxin levels and HCC. Interestingly, Sumida et al. [36] indicated that the mean thioredoxin value was lower in interferon (IFN) responders than in non-responder in patients with type c chronic hepatitis. However, sequence change in serum thioredoxin during IFN therapy and the correlation between thioredoxin and the long-term efficacy of INF treatment should be examined in the future.

In conclusion, to the best of our knowledge, this is the first study to report the clinically diagnostic relevance of thioredoxin as a serum protein marker for $\mathrm{HCC}$ in a training cohort and an independent validation cohort. Our results indicated that serum thioredoxin could complement measurement of AFP in the diagnosis of HCC, especially very early disease, and will help to resolve the deficiencies of AFP in the testing of AFPnegative patients.

\section{PATIENTS AND METHODS}

In our study, training cohort recruited 205 consecutive patients with HCC and 340 controls (120 patients with liver cirrhosis, 120 patients with chronic liver diseases, and 100 healthy individuals) from the Eastern Hepatobiliary Surgery Hospital, Second Military Medical University, Shanghai, China, from December 2010, to December 2013. Validation cohort recruited 274 consecutive patients with HCC and 340 controls (120 
patients with liver cirrhosis, 120 patients with chronic liver diseases, and 100 healthy individuals) from the Zhongda Hospital, Southeast University, Nanjing, China between May 2011 and March 2014. All patients with first-ever HCC underwent curative resection.

Subjects with other conditions, which may alter thioredoxin, such as previous/concomitant other neoplasm, inflammatory, diabetes, chronic kidney disease, severe burn injury and cardiovascular diseases, were excluded. The healthy subjects with normal liver biochemistry, no history of liver disease or alcohol abuse, and no viral hepatitis were enrolled from the Health Physical Examination Center of those two hospitals. There were no significant differences in demographic or clinic pathological characters of patients with HCC between the training and validation cohorts. This study was approved by the Institutional Review Board of the Eastern Hepatobiliary Surgery Hospital of Second Military Medical University and Zhongda Hospital of Southeast University. Informed consent was obtained from each inductee in accordance with the Ethics Committees Guidelines for our institution.

The diagnosis of HCC was made based on guidelines from the Chinese Society of Hepatology and Chinese Society of Infectious Diseases, Chinese Medical Association [46]. The diagnosis of HCC was made either by histopathology or, if not available, by two imaging tests (ultrasound, CT, MRI or angiography) showing an arterial enhancing lesion with a HBV infection background in the Chinese population. The absence of $\mathrm{HCC}$ in patients recruited in the $\mathrm{HCC}$-free chronic liver disease groups was confirmed by ultrasonography at recruitment and 6 months thereafter. HBV infection status was based on hepatitis B surface antigen (HBsAg). HCV infection status was based on serum HCV antibody and HCV RNA determination. Cirrhosis was diagnosed by liver biopsy, abdominal sonography (portal systemic shunts, splenomegaly, spotty coarse parenchyma, nodular surface, and round edge), and biochemical evidence of parenchymal damage plus endoscopic esophageal or gastric varices [47]. Patients with cirrhosis who had raised AFP concentrations were required to have undergone imaging by multiple methods (ultrasonography, CT, or MRI) and to have had no evidence of a hepatic mass for at least 3 months before enrolment. A liver biopsy may be obtained to confirm the diagnosis.

Clinical data collected included age, sex, ChildPugh score, serum alpha-fetoprotein (AFP), viral status, infection time, tumor size and radiological extent of disease. In addition, treatment history, tumor node metastasis (TNM) staging, Edmondson and Steiner grade and etiological risk factors were collated. The tumor size was the largest diameter measured by imaging. $\mathrm{HCC}$ and cirrhotic patients were classified into the three (A/B/C) Child-Pugh's grades based on their clinical state [48]. HCC grading was based on the available material according to Edmondson and Steiner [49], and cases were divided into two groups: well-differentiated histology (G1) and moderately to poorly differentiated histology (G2/G3). Tumor staging (I, II, III, IV) was established using the American Liver Tumor Study Group modified TNM staging classification [50]. In our study, very early HCC was defined as well-differentiated, $<2$-cm HCC [51].

Blood specimens were drawn prior to initiation of treatment (curative resection) for HCC. Venous blood samples were taken in the morning's fasting state. After at least $30 \mathrm{~min}$, but within $2 \mathrm{~h}$, the tubes were centrifuged at $20^{\circ} \mathrm{C}$ for $15 \mathrm{~min}$ at $1,200 \mathrm{~g}$, and the sera were stored frozen in plastic vials at $-80^{\circ}$ until the time of consecutive analyses. The controls samples were collected and stored in the same way as the HCC samples. AFP levels were measured with commercially available immunoassay methods (Axysm). A cut-off value of $20 \mathrm{ng} / \mathrm{mL}$ was used. AFP levels greater than or equal to $20 \mathrm{ng} / \mathrm{mL}$ were defined as positive. Serum levels of thioredoxin was measured in duplicate using a solid-phase sandwich ELISA that uses two highly specific antibodies to human thioredoxin protein; one antibody is precoated onto the thioredoxin ELISA plate and the other antibody is HRP-conjugated (Immuno-Biological Laboratories Co., Ltd, Gunma, Japan) according to the manufacturer's instruction. The coefficients of variation ( $\mathrm{CVs}$ ) of inter-assay and intraassay were $6.0-9.1 \%$ and $7.2-10.0 \%$, respectively. The lower detection limit was $0.45 \mathrm{ng} / \mathrm{mL}$ and the line range was $0.45-100 \mathrm{ng} / \mathrm{ml}$. Other biomarkers, such as white blood cell count (WBC) and high sensitivity $\mathbf{C}$-reactive protein (Hs-CRP) were also tested by standard laboratory method. For all measurements, levels that were not detectable were considered to have a value equal to the lower limit of detection of the assay.

Results are expressed as percentages for categorical variables and as medians (interquartile ranges, IQRs) for the continuous variables. Proportions were compared using the Fisher's exact test, and the Mann-Whitney test to compare continuous variables between groups. Correlations among parameters were analyzed by using Spearman's rank correlation test. The influence of serum thioredoxin levels on HCC was performed by binary logistic regression analysis, which allows adjustment for other confounding factors, such as, sex, age, etiology, family history, $\mathrm{HbsAg}$, HBV copies and serum levels of ALT, AST, total bilirubin, prothrombin time and AFP. Results were expressed as adjusted OR (odds ratios) with the corresponding 95\% Confidence interval (CI). Receiver operating characteristic (ROC) curves were utilized to evaluate the accuracy of serum biomarkers to diagnose HCC. Area under the curve (AUC) was calculated as measurements of the accuracy of the test. All statistical analysis was performed with SPSS for Windows, version 19.0 (SPSS Inc., Chicago, IL, USA) and STATA 9.2 (Stata Corp, College Station, TX), R version 2.8.1. Two-tailed significance values were used and significance levels were set at 0.05 . 


\section{ACKNOWLEDGMENTS}

We also express our gratitude to all the patients who participated in this study, and thereby made this work possible. Authors also acknowledge the contribution of you and the reviewers who have helped us to improve the manuscript.

This work was supported by the State Key Project on Infectious Diseases of China (2012ZX10002-016 to Shen F), and Natural Science and Medical Development Foundation of Shanghai (12ZR1439700 and 134119a7100 to $\mathrm{Li}$ J).

The funding plays no role in the study process.

\section{Authors contributions}

Feng Shen had full access to all the data in the study and is responsible for the integrity of the data and the accuracy of the data analyses. Feng Shen, Jun Li, Yang Liu, Zhang-jun Cheng: study concept and design, and drafting of the manuscript; Jun Li, Zhang-jun Cheng, Zhen-lin Yan, Kui Wang, Dong Wu: acquisition of data; Jun Li, Yang Liu, Zhang-jun Cheng, Xu-ying Wan, Yong Xia: analysis and interpretation of data; Feng Shen, Wan Yee Lau, Meng-chao Wu: critical revision of the manuscript for important intellectual content, and administrative support. All authors have read, edited and approved of the final version of the manuscript.

\section{CONFLICT OF INTEREST STATEMENT}

The authors have no relevant potential conflicts of interest to declare.

\section{REFERENCES}

1. Chen J G, Zhang S W. Liver cancer epidemic in China: past, present and future $[\mathrm{C}] / /$ Seminars in cancer biology. Academic Press 2011; 21: 59-69.

2. Jemal A, Bray F, Center MM, Ferlay J, Ward E, Forman D. Global cancer statistics. CA Cancer J Clin 2011; 61: 69-90.

3. Xu Y, Liu A J, Gao Y X, Hu MG, Zhao GD, Zhao ZM, Liu R. Expression of Ku86 and Presence of Ku86 Antibody as Biomarkers of Hepatitis B Virus Related Hepatocellular Carcinoma. Digestive diseases and sciences, 2014; 59:614-622.

4. Ji J, Shi J, Budhu A, Yu Z, Forgues M, Roessler S, Ambs S, Chen Y, Meltzer PS, Croce CM, Qin LX, Man K, Lo CM, et al. MicroRNA expression, survival, and response to interferon in liver cancer. N Engl J Med. 2009; 361:1437-1447.

5. Zinkin N T, Grall F, Bhaskar K, Otu HH, Spentzos D, Kalmowitz B, Wells M, Guerrero M, Asara JM, Libermann TA, Afdhal NH. Serum proteomics and biomarkers in hepatocellular carcinoma and chronic liver disease. Clinical Cancer Research. 2008; 14:470-477.
6. Yang L, Rong W, Xiao T, Zhang Y, Xu B, Liu Y, Wang L, Wu F, Qi J, Zhao X, Wang H, Han N, Guo S, et al. Secretory/releasing proteomebased identification of plasma biomarkers in HBV-associated hepatocellular carcinoma. Sci China Life Sci. 2013; 56:638-646.

7. Tameda M, Shiraki K, Sugimoto K, Ogura S, Inagaki Y, Yamamoto N, Ikejiri M, Takei Y, Ito M, Nobori T. Desgamma-carboxy prothrombin ratio measured by $\mathrm{P}-11$ and P-16 antibodies is a novel biomarker for hepatocellular carcinoma. Cancer Sci 2013; 104:725-731.

8. Paul D, Biswas R, Habib SH. Tissue polypeptide specific antigen as a marker used to determine the liver diseases. Kathmandu Univ Med J (KUMJ). 2011; 9:24-27.

9. Capurro M, Wanless IR, Sherman M, Deboer G, Shi W, Miyoshi E, Filmus J. Glypican-3: a novel serum and histochemical marker for hepatocellular carcinoma. Gastroenterology 2003; 125:89-97.

10. Taketa K. a-Fetoprotein: reevaluation in hepatology. Hepatology 1990; 12:1420-1432.

11. Johnson PJ. The role of serum alpha-fetoprotein estimation in the diagnosis and management of hepatocellular carcinoma. Clin Liver Dis 2001; 5:145-159.

12. Conrad M, Jakupoglu C, Moreno SG, Lippl S, Banjac A, Schneider M, Beck H, Hatzopoulos AK, Just U, Sinowatz F, Schmahl W, Chien KR, Wurst W, et al. Essential role for mitochondrial thioredoxin reductase in hematopoiesis, heart development, and heart function. Molecular and cellular biology 2004; 24:9414-9423.

13. Bindoli A, Rigobello MP, Scutari G, et al. Thioredoxin reductase: a target for gold compounds acting as potential anticancer drugs. Coordination Chemistry Reviews 2009; 253:1692-1707.

14. Powis G, Montfort WR. Properties and biological activities of thioredoxins. Annu Rev Pharmacol Toxicol 2001; 41:261-295.

15. Kakisaka Y, Nakashima T, Sumida Y, Yoh T, Nakamura H, Yodoi J, Senmaru H. Elevation of serum thioredoxin levels in patients with type 2 diabetes. Hormone and metabolic research 2002; 34:160-164.

16. Tsuchikura S, Shoji T, Shimomura N, Kakiya R, Emoto M, Koyama H, Ishimura E, Inaba M, Nishizawa Y. Serum C-reactive protein and thioredoxin levels in subjects with mildly reduced glomerular filtration rate BMC nephrology. 2010; $11: 7$.

17. Abdiu A, Nakamura H, Sahaf B, Yodoi J, Holmgren A, Rosén A. Thioredoxin blood level increases after severe burn injury. Antioxidants and redox signaling 2000; 2:707-716.

18. Miyamoto S, Kawano H, Sakamoto T, Soejima H, Kajiwara I, Hokamaki J, Hirai N, Sugiyama S, Yoshimura M, Yasue H, Nakamura H, Yodoi J, Ogawa H. Increased plasma levels of thioredoxin in patients with coronary spastic angina Antioxidants and Redox Signaling. 2004; 6:75-80. 
19. Welsh SJ, Bellamy WT, Briehl MM, Powis G. The Redox Protein Thioredoxin-1 (Thioredoxin-1) Increases Hypoxiainducible Factor $1 \alpha$ Protein Expression Thioredoxin-1 Overexpression Results in Increased Vascular Endothelial Growth Factor Production and Enhanced Tumor Angiogenesis. Cancer research 2002; 62:5089-5095.

20. Kakolyris S, Giatromanolaki A, Koukourakis M, Powis G, Souglakos J, Sivridis E, Georgoulias V, Gatter KC, Harris AL. Thioredoxin expression is associated with lymph node status and prognosis in early operable nonsmall cell lung cancer. Clin Cancer Res 2001; 7:3087-3091.

21. Raffel J, Bhattacharyya AK, Gallegos A, Cui H, Einspahr JG, Alberts DS, Powis G. Increased expression of thioredoxin-1 in human colorectal cancer is associated with decreased patient survival. J Lab Clin Med 2003; 142:46-51.

22. Miyazaki K, Noda N, Okada S, Hagiwara Y, Miyata M, Sakurabayashi I, Yamaguchi N, Sugimura T, Terada M, Wakasugi H. EIevated serum level of Thioredoxin in patients with Hepatocellular Carcinoma. Biotherapy 1998; 11:277-288.

23. Zinkin NT, Grall F, Bhaskar K, Otu HH, Spentzos D, Kalmowitz B, Wells M, Guerrero M, Asara JM, Libermann TA, Afdhal NH. Serum proteomics and biomarkers in hepatocellular carcinoma and chronic liver disease. Clin Cancer Res 2008; 14:470-477.

24. Park BJ, Cha MK, Kim IH. Thioredoxin 1 as a serum marker for ovarian cancer and its use in combination with CA125 for improving the sensitivity of ovarian cancer diagnoses. Biomarkers 2014; 19:604-610.

25. Jeng JE, Tsai MF, Tsai HR, Chuang LY, Lin ZY, Hsieh MY, Chen SC, Chuang WL, Wang LY, Yu ML, Dai CY, Tsai JF. Urinary transforming growth factor $\alpha$ and serum $\alpha$-fetoprotein as tumor markers of hepatocellular carcinoma. Tumor Biology 2014; 35:3689-3698.

26. Shen Q, Fan J, Yang X R, Tan Y, Zhao W, Xu Y, Wang N, Niu Y, Wu Z, Zhou J, Qiu SJ, Shi YH, Yu B, et al. Serum DKK1 as a protein biomarker for the diagnosis of hepatocellular carcinoma: a large-scale, multicentre study. The lancet oncology 2012; 13:817-826.

27. Marrero J A, Romano P R, Nikolaeva O, Steel L, Mehta A, Fimmel CJ, Comunale MA, D'Amelio A, Lok AS, Block TM. GP73, a resident Golgi glycoprotein, is a novel serum marker for hepatocellular carcinoma Journal of hepatology. 2005; 43:1007-1012.

28. Cheng ZX, Huang XH, Wang Q, Chen JS, Zhang LJ, Chen XL. Clinical significance of decreased nidogen-2 expression in the tumor tissue and serum of patients with hepatocellular carcinoma. Journal of surgical oncology 2012; 105:71-80.

29. Di Tommaso L, Destro A, Fabbris V, Spagnuolo G, Laura Fracanzani A, Fargion S, Maggioni M, Patriarca C, Maria Macchi R, Quagliuolo M, Borzio M, Iavarone M, Sangiovanni A, et al. Diagnostic performance of clathrin heavy chain staining in a marker panel for the diagnosis of small hepatocellular carcinoma. Hepatology 2011; 53:1549-1557.
30. Nakagawa T, Seki T, Shiro T, Imamura M, Itoh T, Tamai T, Nishimura A, Yamashiki N, Matsuzaki K, Sakaida N, Inoue K, Okamura A. Clinicopathologic significance of protein induced by vitamin $\mathrm{k}$ absence or antagonistic II and alphafetoprotein in hepatocellular carcinoma. Int J Oncol 1999; 14:281-286.

31. Giannelli G, Marinosci F, Trerotoli P, Volpe A, Quaranta M, Dentico P, Antonaci S. SCCA antigen combined with alpha-fetoprotein as serologic markers of HCC. Int J Cancer 2005; 117:506-509.

32. Meng FL, Wang W, Jia WD. Diagnostic and prognostic significance of serum miR-24-3p in HBV-related hepatocellular carcinoma. Medical Oncology 2014; 31:1-6.

33. Zhang Z, Ge S, Wang X, et al. Serum miR-483-5p as a potential biomarker to detect hepatocellular carcinoma. Hepatology International 2013; 7:199-207.

34. Kulasingam V, Diamandis EP. Strategies for discovering novel cancer biomarkers through utilization of emerging technologies. Nat Clin Pract Oncol 2008; 5:588-99.

35. Witjes C DM, van Aalten SM, Steyerberg EW, Borsboom GJ, de Man RA, Verhoef C, Ijzermans JN. Recently introduced biomarkers for screening of hepatocellular carcinoma: a systematic review and meta-analysis. Hepatology international 2013; 7:59-64.

36. Sumida Y, Nakashima T, Yoh T, Nakajima Y, Ishikawa H, Mitsuyoshi H, Sakamoto Y, Okanoue T, Kashima K, Nakamura H, Yodoi J. Serum thioredoxin levels as an indicator of oxidative stress in patients with hepatitis $\mathrm{C}$ virus infection. J Hepatol 2000; 33:616-622.

37. Powis G, Mustacich D, Coon A. The role of the redox protein thioredoxin in cell growth and cancer. Free Radical Biology and Medicine 2000; 29:312-322.

38. Nakamura H, Masutani H, Tagaya $Y$, Yamauchi A, Inamoto $\mathrm{T}$, Nanbu $\mathrm{Y}$, Fujii $\mathrm{S}$, Ozawa $\mathrm{K}$, Yodoi J. Expression and growth-promoting effect of adult t-cell leukemia-derived factor a human thioredoxin homologue in hepatocellular carcinoma Cancer. 1992; 69:2091-2097.

39. Jordan A, Reichard P. Ribonucleotide reductases. Annual review of biochemistry. 1998; 67:71-98.

40. Spector A, Yan GZ, Huang RR, McDermott MJ, Gascoyne PR, Pigiet V. The effect of H2O2 upon thioredoxin-enriched lens epithelial cells. Journal of Biological Chemistry 1988; 263:4984-4990.

41. Björnstedt M, Xue J, Huang W, Akesson B, Holmgren A. The thioredoxin and glutaredoxin systems are efficient electron donors to human plasma glutathione peroxidase. Journal of Biological Chemistry 1994; 269:29382-29384.

42. Iwata S, Hori T, Sato N, Hirota K, Sasada T, Mitsui A, Hirakawa T, Yodoi J. Adult T cell leukemia (ATL)-derived factor/human thioredoxin prevents apoptosis of lymphoid cells induced by L-cystine and glutathione depletion: possible involvement of thiol-mediated redox regulation in apoptosis caused by pro-oxidant state. The Journal of Immunology 1997; 158:3108-3117. 
43. Sumida Y, Nakashima T, Yoh T, Furutani M, Hirohama A, Kakisaka Y, Nakajima Y, Ishikawa H, Mitsuyoshi H, Okanoue T, Kashima K, Nakamura H, Yodoi J. Serum thioredoxin levels as a predictor of steatohepatitis in patients with nonalcoholic fatty liver disease J Hepatol 2003; 38:32-38.

44. Tamai T, Uto H, Takami Y, Oda K, Saishoji A, Hashiguchi M, Kumagai K, Kure T, Mawatari S, Moriuchi A, Oketani M, Ido A, Tsubouchi H. Serum manganese superoxide dismutase and thioredoxin are potential prognostic markers for hepatitis $\mathrm{C}$ virus-related hepatocellular carcinoma. World J Gastroenterol 2011; 17:4890-4898.

45. Zhang XY, Chen DC, Xiu MH, Yang FD, Tan YL, He S, Kosten TA, Kosten TR. Thioredoxin, a novel oxidative stress marker and cognitive performance in chronic and medicated schizophrenia versus healthy controls. Schizophrenia research 2013; 143:301-306.

46. Mao Y, Yang H, Xu H, Lu X, Sang X, Du S, Zhao H, Chen W, Xu Y, Chi T, Yang Z, Cai J, et al. Golgi protein 73 (GOLPH2) is a valuable serum marker for hepatocellular carcinoma. Gut 2010; 59:1687-1693.
47. Tsai JF, Chang WY, Jeng JE, Wang LY, Hsieh MY, Chen SC, et al. Hepatitis $\mathrm{C}$ virus infection as a risk factor for non-alcoholic liver cirrhosis in Taiwan. J Med Virol 1993; 41:296-300.

48. Pugh RN, Murray-Lyon IM, Dawson JL, Peitroni MC, Williams R. Transection of the esophagus for bleeding esophageal varices. Br J Surg 1973; 60:646-649.

49. Edmondson HA, Steiner PE. Primary carcinoma of the liver. A study of 100 cases among 48, 900 necropsies. Cancer 1954; 7:462-503.

50. American Liver Tumor Study Group: A randomized prospective multi-institutional trial of orthotopic liver transplantation or partial hepatic resection with or without adjuvant chemotherapy for hepatocellular carcinoma. Investigators Booklet and Protocol. 1998; United Network for Organ Sharing Policy 3.6.4.4.

51. International Consensus Group for Hepatocellular Neoplasia: Pathologic diagnosis of early hepatocellular carcinoma: a report of the international consensus group for hepatocellular neoplasia. Hepatology 2009; 49:658-664. 